\title{
Population Analysis: Communicating About Anthropometry in Context
}

Sherry Thaxton, Ph.D. Lockheed Martin Houston, TX

Sudhakar Rajulu, Ph.D. NASA-Johnson Space Center Houston, TX

HSI Knowledge Broadcast July 21, 2009 
- Presentation background

- Introduction

- Definition of population analysis

- Major applications

- Case studies

- Summary and conclusions

- References 
- Based on a paper submitted to the 2008 Human Factors and Ergonomics Society

Conference

- Presented at HFES in September 2008

- Primarily focused on anthropometry, though other applications exist

- Case studies based on work performed in JSC's Anthropometry and Biomechanics Facility 


\section{Introduction}

- Providing anthropometric accommodation for an entire range of the population

- Widely accepted philosophy

- Not always simple to define or achieve

- Communication of issues with human-system integration is critical

- Population analysis applies existing human factors methodologies in novel ways to assist with this communication 
- Population analysis places human subject data such as anthropometry and strength into the context of the entire user population

- Define test subjects based on comparisons to the extremes of the expected population

- Compare hardware dimensions against a large sample population database of potential users

- End result: better definition of subject accommodation 


\section{Definition}

- Accommodation, usability, and operability into the context of the overall user population

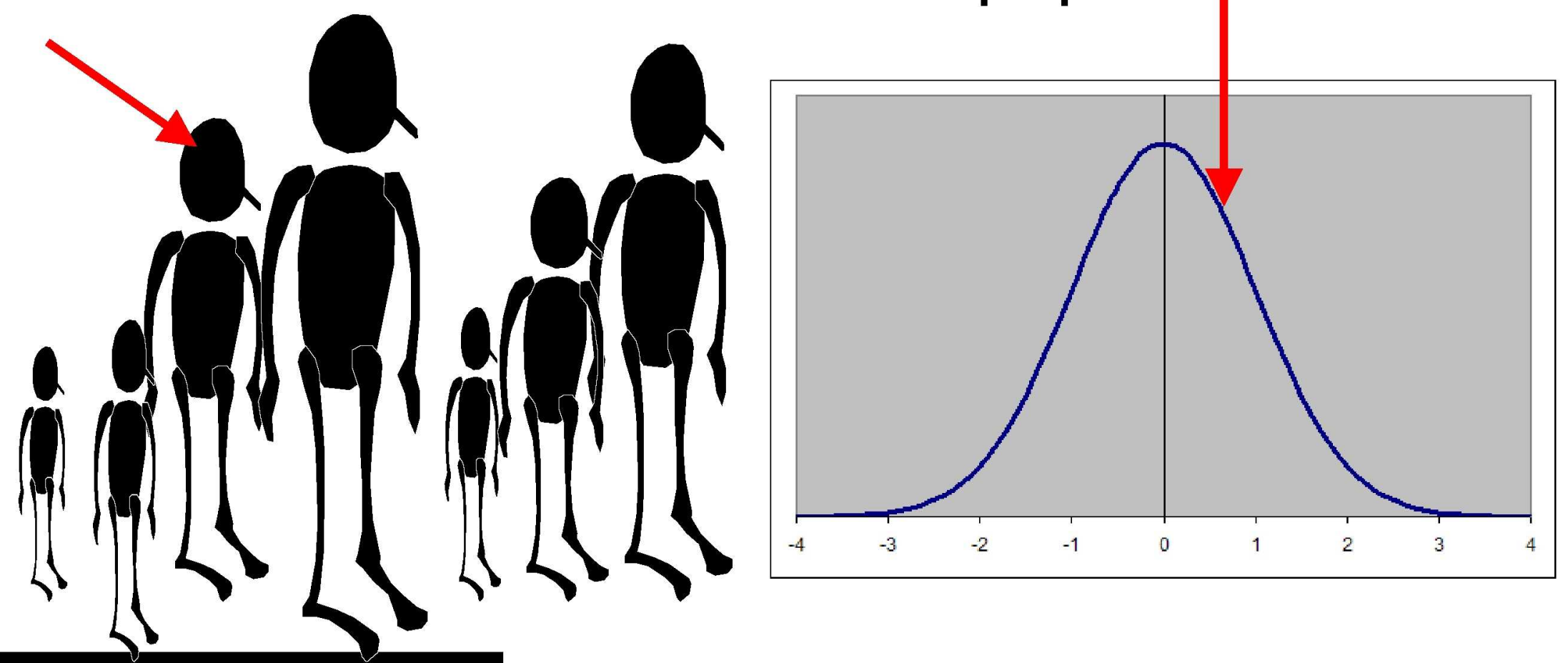




\section{Value of Population Analysis}

- Provides advantages over traditionally used techniques

- Random sampling may not provide adequate representation of population

- Methods such as principle component analysis leave a large portion of variance unexplained

- Statistics can rely on bad assumptions (linearity, normality) and be difficult to communicate meaning to engineers 


\section{Major Applications}

- Analysis of multivariate problems

- Analyzing more than one anthropometric variable allows a greater understanding beyond simple onedimensional cases

- Enhancement of human-in-the-loop testing

- Subject feedback becomes more valuable when it is examined within the context of the population as a whole 
- Design of a doorway

- One-dimensional problem- height of doorway

- If height of doorway is equivalent to $90^{\text {th }}$ percentile male stature, about 10 percent of the male population will experience difficulty walking through

- Two-dimensional problem- height and width of doorway

- If height and width are both equivalent to $90^{\text {th }}$ percentile male dimensions (stature and bideltoid breadth), additional members of population will experience difficulty

- Stature is not highly correlated with width measurements (Kroemer, Kroemer, and Kroemer-Elbert, 1994)

- Percent of population experiencing difficulties with door will fall between 10 and 20 percent

- Analysis of sample database allows determination of reasonable estimate of percent accommodated 
Enhancement of Human-in-the-

\section{Loop Testing}

- Consider doorway from previous example

- A group of 10 subjects walks through and determine that doorway is completely acceptable

-What were the largest statures and bideltoid breadths?

- If subjects represented extremes of the population, their evaluation holds more power

- Even if subjects did not represent extremes, placing their anthropometry into context holds

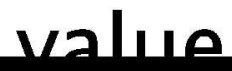




\section{Case Studies}

- Case study background

- Performed at NASA-Johnson Space Center (JSC)

- Associated with development of hardware for the Constellation Program

- Population analysis performed by staff of the Anthropometry and Biomechanics Facility (ABF)

- Space Suit Critical Dimensions

- Lunar Lander Vehicle Design 


\section{Space}

\section{Sult}

\section{Dimensions}

- Constellation Program anthropometry requirements are defined in Human-System Integration Requirements

- List of critical dimensions

- Formulated among spacesuit and cockpit design teams and human factors practitioners

- $1^{\text {st }}$ percentile female through $99^{\text {th }}$ percentile male accommodated

- Astronaut database is based on modified 1988 Army data (ANSUR) 


\section{Limited Dimensions}

- Space suit designers indicated that it was infeasible to accommodate the full anthropometric range

- Provided list of body dimensions they considered to be reasonable

- Further analysis was needed to define accommodation 


\section{Population Analysis of Suit Critical}

Dimensions

- Entire Constellation database filtered through minimum and maximum values provided by

suit designers

- Fourteen dimensions provided

- Any subject falling outside of the range for at least one dimension eliminated

- Resulted in final list of subjects falling within range for all dimensions 


\section{Population Analysis

\section{Dimensions}

- Example:

- Suit design team indicated that it was possible to accommodate between 61.0 and 73.9 inch stature

- Stature of each subject compared against these limits

- Any subject falling outside of range removed from pool to compare to additional dimensions

- Percent of male and female subjects in database accommodated calculated directly 


\section{Results of Analysis}

- Based on initial dimensions provided

- Female accommodation unacceptable

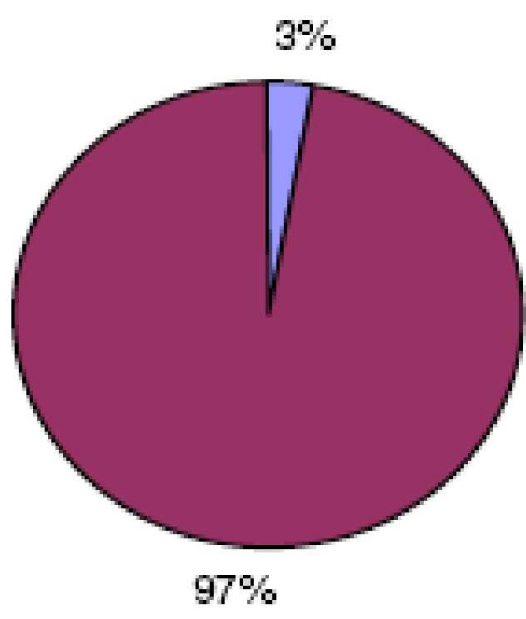

$\square$ Females accommodated - Females not accommodated

- Male accommodation less than expected 


\section{Contribution \\ of \\ Population \\ Analysis}

- Illustrating the levels of accommodation added significant value to communication between HF practitioners and suit designers

- Ultimately, designers concluded that their perceived limitations were more stringent than was realistic

- Analysis of the same 14 critical dimension with $1^{\text {st }}$ percentile female to $99^{\text {th }}$ percentile male performed

- Yielded better than 90 percent accommodation for both genders 
- Altair ascent stage will carry astronauts between the Orion

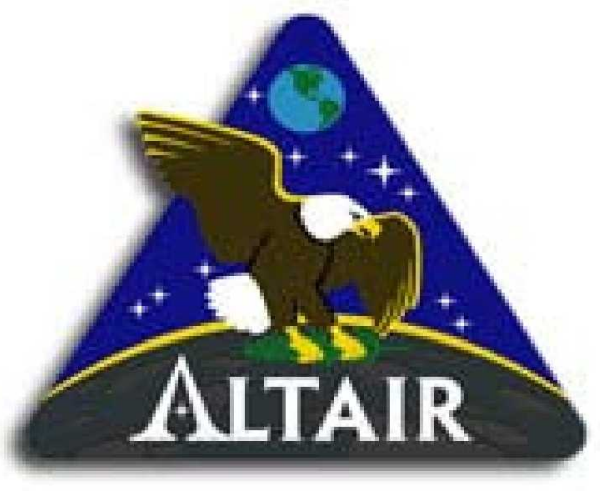
capsule and the surface of the moon

- JSC's Habitability Design Center built a low-fidelity mock-up to evaluate the interior dimensions of the vehicle

- Goal of testing- determine whether internal volume provides space for tasks such as accessing storage and using vehicle controls while wearing a spacesuit 


\section{Concept Art of Altair}

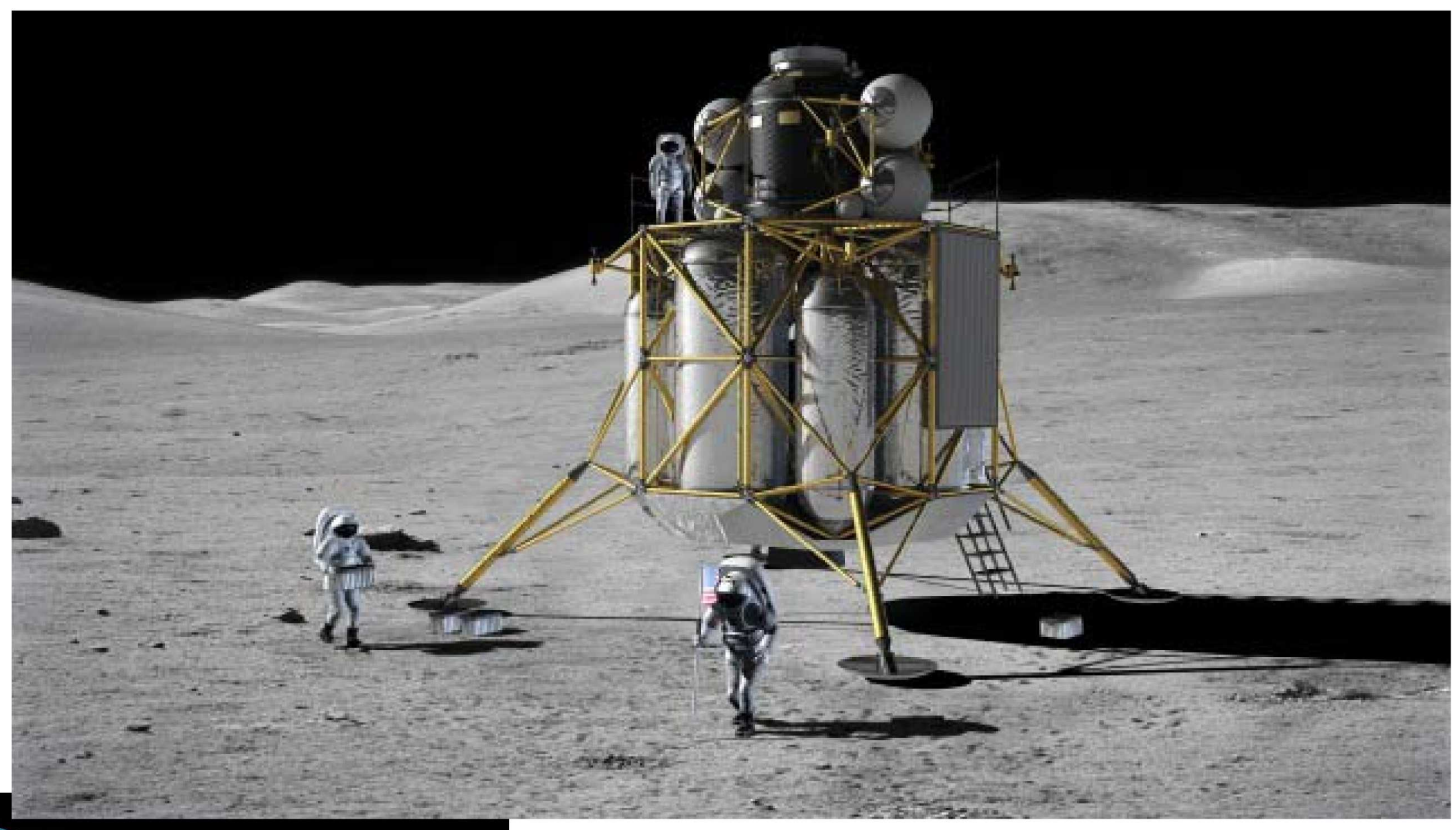




\section{Suits Tested}

- Vehicle designed to carry four suited astronauts - Limited prototype suits available (number and sizes)

- Tested subjects in two types of suits

- Mark III- lunar surface prototype

- Advanced Crew Escape Suit (ACES)- launch/re-entry suit for Shuttle

- Also used a non-functional simulated Mark III suit 
- Video data

- Detect collisions

- Anthropometry

- Minimally clothed data collected from subjects

- Allowed for comparison against expected population

- Major focus of analysis: Larger suit 


\section{Results of Altair Evaluation}

- Subject's bideltoid breadth and forearm-forearm breadth were smaller than average male values

- Collisions still occurred between subject and person wearing mock-up suit

- This highlights likelihood

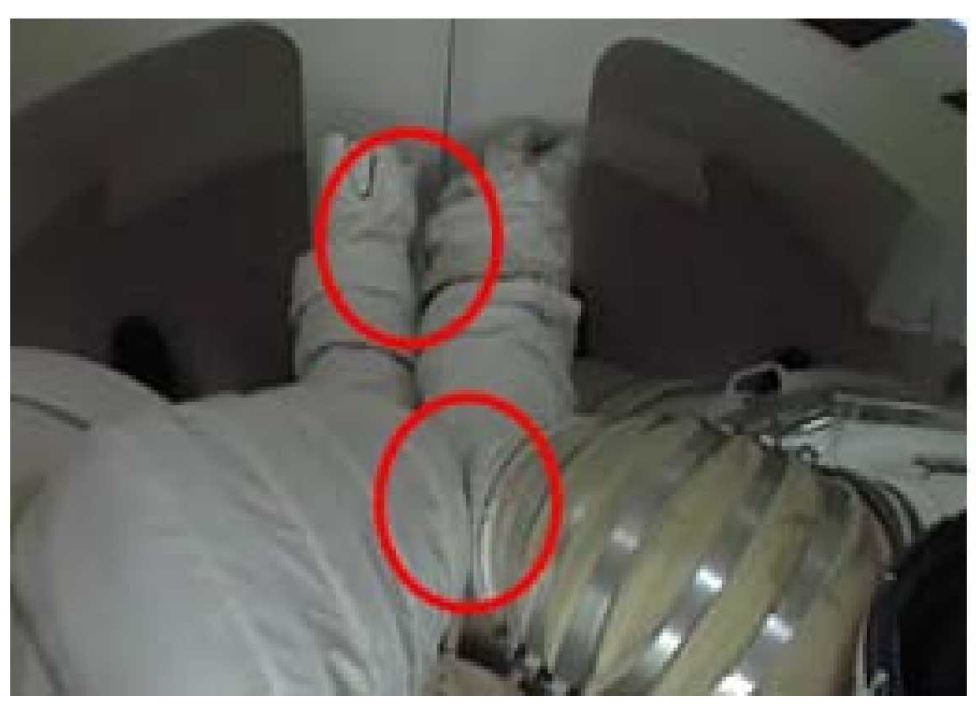
of larger subjects experiencing more difficulty 


\section{Additional Analysis}

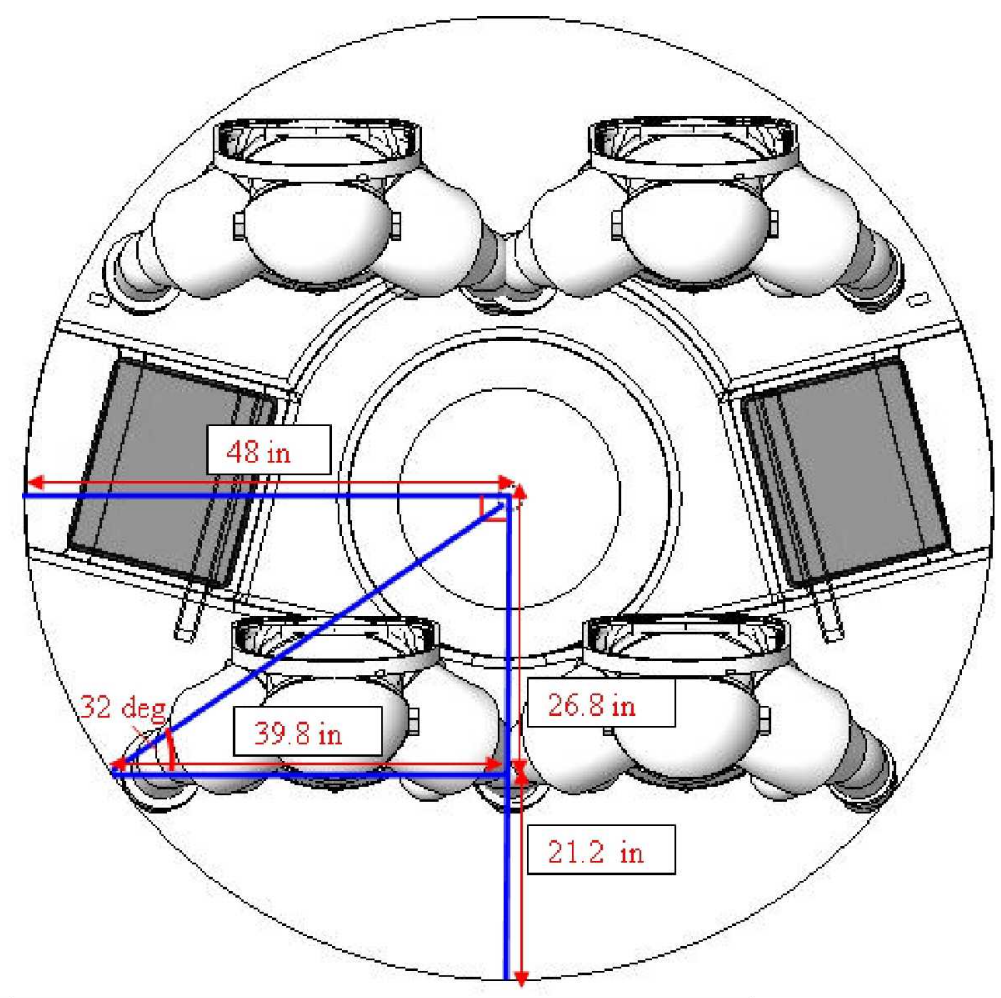

- Mathematical analysis

- Four hypothetical large males wearing spacesuits

- Provided information concerning clearance and fit issues 


\section{Contribution

- Placing the single subject into the context of population provided perspective

- Highlighted need to examine extreme bideltoid and forearm-forearm breadth

- Testing multiple subjects of varying sizes was unrealistic

- Additional analysis added value to the single subject evaluation 


\section{Conclusions}

- Quantifying accommodation levels enables human factors practitioners and design engineers to understand the impact of design decisions

- Placing human factors information into context is an important step in the design process

- Utilizing databases to quantify accommodation - Defining human subjects against the population 


\section{References}

- Human-Systems Integration Requirements (2007), CxP 70024. NASA, Houston, TX.

- Gordon et al (1988). 1988 Anthropometric Survey of U.S. Army Personnel: Methods and Summary Statistics. Tech. Report 90/044. U.S. Army Natick Research, Development, and Engineering Center, Natick, MA.

- Kroemer, K., Kroemer, H. and KroemerElbert, K (1994). Ergonomics: How to design for ease and efficiency. Englewood Cliffs, NJ: Prentice Hall. 
Sherry Thaxton, Ph.D.

CXP Human SIG/Orion Human Engineering

Lockheed Martin

281-483-7413

sherry.s.thaxton@nasa.gov 